\title{
Status Kebersihan Mulut dan Karies Pada Siswa Berkebutuhan Khusus di SLB Autis dan TPA B SLB Branjangan Kabupaten Jember
}

\author{
Dessy Rachmawati, Tantin Ermawati \\ Biomedik Fakultas Kedokteran Gigi Universitas Jember \\ d.rachmawati@unej.ac.id
}

\begin{abstract}
Abstrak
Kesehatan rongga mulut merupakan bagian penting dari kesehatan secara menyeluruh. Gigi merupakan salah satu organ pencernaan paling penting dalam proses pencernaan makanan, sehingga kesehatan gigi merupakan salah satu hal terpenting bagi pertumbuhan anak. Tingginya resiko karies gigi pada anak-anak disebabkan karena secara fisiologis-anatomi gigi sulung mempunya pit dan fissure yang lebih dalam sehingga memudahkan plak menempel. Selain itu, konsumsi gula yang tinggi pada anakanak memicu proses terjadinya kerusakan gigi (Suwelo, I.S. 1992). Anak-anak berkebutuhan khusus merupakan kelompok berisiko tinggi terhadap masalah kesehatan sehingga membutuhkan bantuan dan kerjasama dengan orang lain untuk mendapatkan dan memelihara kesehatan, termasuk dalam menjaga kesehatan gigi dan mulut mereka. Kondisi gigi dan mulut yang bersih dan sehat sangat penting untuk menunjang kehidupan anak-anak tersebut. Masalah gigi yang biasanya muncul pada anak berkebutuhan khusus antara lain karies (lubang) gigi, gigi berdarah, dan gigi berjejalan (maloklusi). Oleh karena itu, anak-anak berkebutuhan khusus lebih membutuhkan perhatian dibandingkan anak-anak normal lainnya karena berbagai keterbatasan yang dimiliki terutama kurang mampu untuk membersihkan sendiri rongga mulutnya. Sehingga hal ini meningkatkan faktor resiko kerusakan gigi-gigi dan jaringan lunak rongga mulut disekitarnya. Penelitian ini bertujuan untuk mengetahui tingkat kebersihan rongga mulut dan status kesehatan rongga mulut serta hubungan antara tingkat kebersihan rongga mulut dengan status gingivitis/penyakit periodontal pada siswa autis. Jenis penelitian ini adalah anayitic correlation dengan pendekatan cross sectional, sampel diambil menggunakan teknik accidental sampling dengan uji statistik KolmogorovSmirnov. Subjek adalah 35 siswa autis di SLB Autis dan TPA B SLB Branjangan Kabupaten Jember. Hasil penelitian menunjukkan tingkat kebersihan mulut siswa autis di SLB Branjangan sebagian besar adalah sedang $(57,1 \%)$ dan sebagian besar siswa yang diperiksa mengalami karies dan penyakit periodontal sedang (70\%). Semua siswa yang diperiksa mengalami karies, baik itu siswa dengan tingkat kebersihan mulut yang baik, sedang maupun buruk. Disarankan kepada siswa autis tersebut untuk selalu menjaga kebersihan dan kesehatan rongga mulutnya.
\end{abstract}

Kata Kunci : siswa autis, anak berkebutuhan khusus, karies, tingkat kebersihan rongga mulut

\begin{abstract}
Oral health is an important part of overall health. Teeth are one of the most important digestive organs in the process of digestion of food, and as such dental health becomes an instrumental part of a child's developmental health. The high risk of dental cavities in children is caused by physiologically-anatomic primary teeth having deeper pits and fissures which allow plaque to more easily stick to teeth. In addition, high sugar consumption in children triggers the process of tooth decay (Suwelo, I.S. 1992). Children
\end{abstract}


with special needs are a high risk group for health problems because they are heavily reliant on others in maintaining their hygiene and health. Dental problems that usually occur in children with special needs include dental cavities (holes), bleeding teeth, and crammed teeth (malocclusion). This study aims to determine the level of oral hygiene and the significance of gingivitis / periodontal disease specifically in autistic students. This study uses an analytic, cross sectional approach, that takes advantage of accidental sampling technique with the Kolmogorov-Smirnov statistical test. The study particpants were 35 autistic students at Autism SLB and TPA B SLB Branjangan within the Jember Regency. The results showed that the level of oral hygiene of autistic students in SLB Branjangan was mostly moderate $(57.1 \%)$ and most of the students examined had cavities and moderate periodontal disease $(70 \%)$. All students examined had cavities, regardless of the level of oral hygiene. Keywords : autistic students, children with special needs, caries, oral hygiene level

\section{PENDAHULUAN}

Anak-anak berkebutuhan khusus merupakan kelompok berisiko tinggi terhadap masalah kesehatan sehingga membutuhkan bantuan dan kerjasama dengan orang lain untuk mendapatkan dan memelihara kesehatan, termasuk dalam menjaga kesehatan gigi dan mulut mereka. Kondisi gigi dan mulut yang bersih dan sehat sangat penting untuk menunjang kehidupan anak-anak tersebut. Oleh karena itu, para orang tua dan juga guru sebaiknya memahami prinsip pemeliharaan kesehatan pada anak-anak berkebutuhan khusus.

Kesehatan gigi merupakan salah satu hal terpenting bagi pertumbuhan anak. Namun, di Indonesia tidak banyak orang tua yang peduli akan kesehatan gigi anak, terlebih pada anak dengan kebutuhan khusus (disabled children). Mereka (anak berkebutuhan khusus) adalah anak-anak yang mengalami gangguan mental seperi autisme, down syndrome dan cerebral palsy, dan idquo. Masalah gigi yang biasanya muncul pada anak berkebutuhan khusus antara lain karies (lubang) gigi, gigi berdarah, dan gigi berjejalan (maloklusi). Anak-anak berkebutuhan khusus lebih membutuhkan perhatian khusus dibanding anak-anak normal lainnya karena berbagai keterbatasan yang ada pada mereka, diantaranya adalah kurang mampu untuk membersihkan sendiri rongga mulutnya. Sehingga hal ini meningkatkan faktor resiko kerusakan gigi-gigi dan jaringan lunak disekitarnya (Chamidah, AN. 2010; Jain, M et al. 2009)

Masalah kesehatan gigi dan mulut yang sering dialami anak-anak berkebutuhan khusus :

1. Gigi berlubang (karies gigi) disebabkan antara lain oleh kelainan bentuk dan struktur gigi (anomali), frekuensi muntah atau gastroesophangeal refluks, jumlah air ludah kurang atau berlebih, pengobatan yang mengandung gula atau diet khusus yang memerlukan pemberian susu botol yang diperpanjang 
dan keterbatasan anak ataupun kemauan dari orang-orang sekitar untuk membantu membersihkan gigi dan mulut secara rutin setiap hari.

2. Penyakit jaringan penyangga gigi (periodontal) seperti gusi berdarah, kegoyongan gigi dan karang gigi. Kondisi ini disebabkan oleh kebersihan mulut yang kurang diperhatikan karena ketidakmampuan menggunakan sikat gigi dengan benar, pola makan yang kurang baik dan efek samping dari obatobatan yang dikonsumsi. Radang pada jaringan periodontal yang parah dapat mengakibatkan anak kehilangan gigi.

3. Maloklusi terjadi karena adanya keterlambatan erupsi gigi, tidak ada benih gigi, gigi berlebih, gangguan fungsi hubungan otot-otot dalam mulut dan periodontal sehingga rahang atas maju, gigitan terbuka dan gigitan silang. Bruksism (ngerot) pada penderita cerebral palsy mengakibatkan gigi rahang atas maju ke depan. Untuk menangani bruksism dapat digunakan bite guard.

4. Bernafas melalui mulut (pernapasan mulut kronik) disebabkan oleh jalan nafas yang lebih sempit sehingga anak berkebutuhan khusus cenderung bernafas melalui mulut. Pernafasan mulut kronis ini menyebabkan ukuran lidah membesar (makroglosia) dan permukaan lidah beralur dalam dan kering sehingga menimbulkan bau mulut (halitosis) dan iritasi pada sudut bibir (angular cheilitis). Kondisi ini akan mempengaruhi fungsi bicara dan pengunyahan.

5. Trauma atau benturan sering terjadi pada anak-anak dengan gangguan psikososial dan perilaku karena jatuh ataupun kecelakaan.

a)

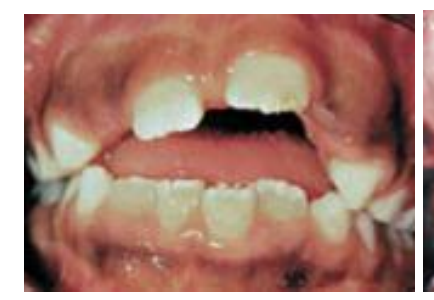

a)Maloklusi; b) Karies; c) radang gusi pada anak berkebutuhan khusus b)

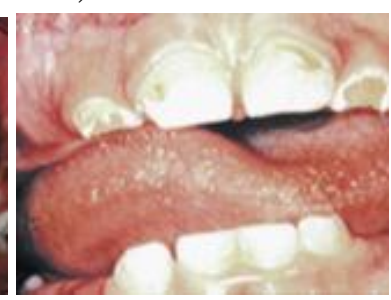

c)

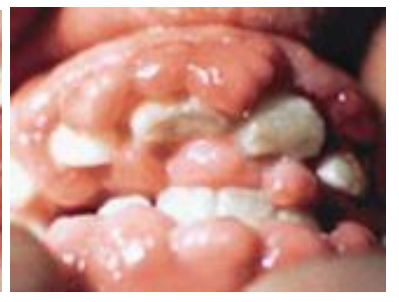

SLB khusus anak autisme ini terletak kurang lebih $3 \mathrm{~km}$ dari pusat kota Kabupaten Jember. SLB ini memiliki 30 anak didik yang menderita autisme. Data prevalensi penyakit gigi dan mulut belum tercatat dengan baik pada SLB ini, sehingga perlu segera dilakukan pendataan untuk mengetahui tingkat kesehatan anak-anak berkebutuhan khusus ini secara tepat. Sehingga dapat ditentukan penatalaksanaan yang tepat untuk meningkatkan kesehatan gigi dan mulutnya.

Hasil penelitian ini diharapkan dapat memberikan data yang akurat tentang prevalensi karies dan kebutuhan perawatan gigi pada anak berkebutuhan khusus terutama anak-anak penderita autisme. Selanjutnya, dapat 
merekomendasi suatu model pendekatan Tell Show Do yang dapat digunakan sebagai teknik yang efisien dan efektif, digunakan untuk anak-anak autisme dalam meningkatkan status kesehatan gigi dan rongga mulutnya. Hal ini penting mengingat perawatan kesehatan gigi dan mulut pada anak-anak autisme berbeda dibandingkan pada anak yang normal.

\section{METODE PENELITIAN}

Jenis penelitian ini adalah deskriptif. Metode pengumpulan data dari berbagai sumber di lapangan. Data yang digunakan adalah data primer dan data sekunder. Penelitian ini dilaksanakan di SLB B dan TPA Autis SLB Branjangan pada bulan November 2018. Populasi yaitu siswa autisme, berusia 8-17 tahun berjumlah 35 orang. Total sampling merupakan metode penelitian yang digunakan untuk menentukan subyek penelitian. Instrumen yang digunakan dalam penelitian ini adalah alat dasar kedokteran gigi (kaca mulut, sonde, pinset), disclosing solution dan formulir pemeriksaan OHI-S.

Data yang dikumpulkan meliputi hasil pengukuran tingkat kebersihan gigi dan mulut siswa autis yang kemudian dikode sesuai dengan indeks Oral Hygiene Index Simplifield (OHI-S) menurut Greene dan Vermilion serta hasil pengukuran indeks gingiva anak autis yang kemudian dikode sesuai dengan Indeks Karies dan Gingiva dari Loe dan Sillness sehingga didapatkan hasil pengukuran status gingivitis.

\section{HASIL DAN PEMBAHASAN}

Tabel 1. Distribusi karakteristik jumlah siswa autis berdasarkan tingkat usia sekolah

\begin{tabular}{|c|c|c|c|}
\hline No & Kategori Pendidikan & Jumlah & Persentase \\
\hline 1 & SD & 12 & $35 \%$ \\
\hline 2 & SMP & 13 & $37 \%$ \\
\hline 3 & SMA & 10 & $28 \%$ \\
\hline \multicolumn{2}{|c|}{ TOTAL } & 35 & $100 \%$ \\
\hline
\end{tabular}

Usia sekolah dan tingkat pendidikan siswa autis di SLB Branjangan hampir rata dengan jumlah siswa SD sebanyak 12 orang (35\%), SMP masing-masing berjumlah $13(35 \%)$, dan SMA 10 orang $(28 \%)$. 
Tabel 2. Distribusi karakteristik kesehatan rongga mulut berdasarkan OHI-S

\begin{tabular}{|c|c|c|c|}
\hline No & Kategori OHIS & Jumlah & Persentase \\
\hline 1 & Baik (0-1,2) & 7 & $20 \%$ \\
\hline 2 & Sedang $(1,3-3,0)$ & 23 & $66 \%$ \\
\hline 3 & Buruk (3,1-6,0) & 5 & $14 \%$ \\
\hline \multicolumn{2}{|c|}{ TOTAL } & 35 & $100 \%$ \\
\hline
\end{tabular}

Tingkat OHI-S siswa autis yang paling banyak dijumpai pada kategori sedang sekitar 23 orang (66\%), kategori OHIS baik berjumlah 7 (20\%), dan kategori buruk berjumlah 5 orang (14\%).

Tabel 3. Distribusi karakteristik penyakit karies berdasarkan Caries Index

\begin{tabular}{|c|c|c|c|}
\hline No & Kategori Karies Index & Jumlah & Persentase \\
\hline 1 & Sehat & 3 & $9 \%$ \\
\hline 2 & karies Ringan $(0,1-1,0)$ & 7 & $20 \%$ \\
\hline 3 & $\begin{array}{c}\text { karies Sedang } \\
(1,2-2,0)\end{array}$ & 18 & $51 \%$ \\
\hline 4 & $\begin{array}{c}\text { karies berat } \\
(2,1-3,0)\end{array}$ & 7 & $20 \%$ \\
\hline \multicolumn{2}{r|}{ TOTAL } & 35 & $100 \%$ \\
\hline
\end{tabular}

Tingkat karies indeks siswa autis yang paling banyak dijumpai pada kategori karies sedang sekitar 18 orang (51\%) Untuk siswa autis dengan kategori karies ringan berjumlah 7 (20\%), dan karies berat 20\% serta yang sehat 3 (9\%).

Hal ini didukung oleh penelitian yang dilakukan oleh Mawardiyanti (2012) dan Christavia, JM. dkk (2017) yang mendapatkan siswa autis dengan status karies dan kebersihan rongga mulut yang moderat atau sedang. Kesehatan rongga mulut dipengaruhi oleh perilaku masing-masing individu untuk menjaga kebersihan gigi dan jaringan sekitarnya. Perilaku ini sebagian besar dipengaruhi oleh lingkungan melalui pengalaman yang diperoleh dari lingkungan baik keluarga, di sekolah maupun masyrakat (Widi, ER. 2006).

Perilaku menggosok gigi yang benar merupakan salah satu hal yang penting dalam mengurangi terjadinya penyakit gigi seperti karies dan jaringan periodontal. Pada anak autis dibutuhkan metode yang efektif agar anak mau menyikat gigi misalnya dengan menggunakan sikat gigi elektrik sehingga pergerakan sikat dapat lebih terkontrol dengan mudah mengingat keterbatasan fisik dan mental. Selain itu dibutuhkan perhatian yang ekstra dari lingkungan sekitar seperti keluarga dan guru untuk membantu siswa dalam menjaga kebersihan rongga mulutnya. Edukasi melalui penyuluhan dan memberikan pelatihan tentang pentingnya menjaga kebersihan gigi dan mulut pada siswa 
autis masih perlu dilakukan secara periodik sehingga peningkatan status kesehatan secara umum juga dapat meningkat lebih baik lagi.

\section{KESIMPULAN}

Umumnya status OHI-S anak autis di SLB Branjangan berada pada kategori sedang dengan indeks OHI-S rata-rata yaitu 2,00. Edukasi melalui penyuluhan dan memberikan pelatihan tentang pentingnya menjaga kebersihan gigi dan mulut pada siswa autis perlu dilakukan secara periodik sehingga peningkatan status kesehatan gigi dan kesehatan secara umum juga dapat meningkat lebih baik lagi. Hal ini juga dapat meningkatkan derajat hidup anak-anak dengan keterbatasan seperti pada anak-anak autisme ini.

\section{REFERENSI}

Chamidah AN, Pendidikan inklusif untuk anak dengan kebutuhan khusus. Jurnal Pendidikan Khusus. 2010;7(2):1-5.

Christavia J. Motto, Christy N. Mintjelungan, Shane H. R. Ticoalu, Gambaran kebersihan gigi dan mulut pada siswa berkebutuhan khusus di SLB YPAC Manado, Jurnal e-GiGi (eG), 2017; Volume 5 Nomor 1, Januari-Juni

Jain M, Marthur A, Sawla L, Choudhary G, Kabra K, Duraiswamy P. Oral health status of mentally disabled subjects in India. J Oral Sci. 2009;51(3):333-40.

Mawardiyanti NS. Status kebersihan gigi dan mulut serta karies pada anak berkebutuhan khusus di SLB Bintoro Jember [Skripsi]. Jember: Universitas Jember, 2012

Suwelo, I.S. Karies Gigi Pada Anak Dengan Pelbagai Faktor Etiologi.Jakarta :EGC, 1992

Widi ER. Hubungan perilaku membersihkan gigi terhadap tingkat kebersihan mulut siswa sekolah dasar negeri wilayah kerja Puskesmas Gladak Pakem Kabupaten Jember. JKGI. 2006;10(3):10. 